\title{
Antidepressants as a New Approach for Protective Interventions of Cisplatin-Induced Nephrotoxicity
}

Amr A EL-Arabey* and Adel R Abd-Allah

Pharmacology and Toxicology Department, Faculty of Pharmacy, Al-Azhar University, Nasr City, Cairo, Egypt

\begin{abstract}
Cisplatin is a chemotherapy drug that is used to treat different types of cancer, including testicular cancer, germ cell cancer, bladder cancer, cervical cancer, small cell and non-small cell lung cancer, head and neck cancer and others. Its chief dose-limiting side effect is nephrotoxicity, which evolves slowly and predictably after initial and repeated exposure. Organic cation transporter-2 is responsible for cisplatin uptake in the kidney. In this article we will underline the use of antidepressant as a new approach for protective interventions of cisplatin-induced nephrotoxicity through the interference of cisplatin uptake by Organic Cation Transporter-2 to improve the therapeutic index of cisplatin and to treat depression which occurs in cancer patients together after considering the risk of side effects and interactions.
\end{abstract}

Keywords: Cisplatin; Nephrotoxicity; Antidepressant; New; protective approach

\section{Introduction}

Cisplatin (CP) is an inorganic platinum-based chemotherapeutic agent that is widely used in the treatment of a variety of solid organ cancers [1]. The main dose-limiting side effect of CP is nephrotoxicity [2]. After a single dose of CP $\left(50-100 \mathrm{mg} / \mathrm{m}^{2}\right)$, approximately onethird of the patients develop nephrotoxicity [3]. The CP chief doselimiting nephrotoxic side effect requires a reduction of the dose or discontinuation of treatment [4]. Inflammation, endoplasmic reticulum stress and oxidative stress contribute to CP-induced kidney toxicity. In turn, $\mathrm{CP}$ disturbs the oxidant/antioxidant balance and its nephropathy is closely associated with an increase in lipid peroxidation which consequences from an increased quantity of reactive oxygen species in kidney or a decrease of natural cell antioxidant capacity [5-7].

Amifostine is approved by the U.S. Food and Drug Administration for use in reducing progressive nephrotoxicity of repeated CP dosing in patients with advanced ovarian cancer [8]. Amifostine may derive its protective effects by providing a thiol group to normal versus malignant cells [9]. Unfortunately, even with amifostine, renal toxicity still occurs. This has prompted the development of more effective preventive strategies. These strategies can be organized according to putative mechanisms (A) reduced renal CP uptake or activation, (B) administration of anti-oxidants compounds, (C) administration of antiapoptotic compounds and (D) administration of anti-inflammatory compounds. Renal toxicity from $\mathrm{CP}$ derives from the uptake and activation of platinum within the proximal tubule cell. Therefore, maneuvers which differentially reduce $\mathrm{CP}$ uptake, or activated by the kidney relative to tumor cells, should reduce nephrotoxicity without reducing anti-tumor responses [10].

The organic cation transporters (OCTs) have been implicated in CP uptake [11]. Cisplatin-induced tubular cell injury may be related to basolateral OCT [12]. Three isoforms of OCTs are expressed in renal proximal tubules, mainly on the basolateral side [13]. Moreover, it has been demonstrated that OCT2 is the critical OCT responsible for $\mathrm{CP}$ uptake in the kidney and that CP uptake is increased by OCT2 over expression in Human Embryonic Kidney (HEK293) cells, which is associated with increased cellular sensitivity to CP toxicity [14]. OCT2 is most vigorously expressed in the kidney and is also expressed in the small intestine, lung, skin, placenta, brain and choroid plexus $[15,16]$.
In the human kidney OCT2 is expressed in all three segments of proximal tubules and in small intestine, which localized mainly to the basolateral membrane of epithelial cells and to the luminal membrane of epithelial cells in trachea and bronchi $[15,17,18]$. OCT2 is expressed on the apical ventricular membrane epithelial cells of the choroid plexus in the brain. Furthermore, in the basolateral membrane of the distal tubule in the kidney. OCT2 mediates uptake from the blood to the proximal tubular cells during the renal secretion of organic cations. Interestingly, OCT2 plays an important role on the pharmacological, pharmacokinetic and toxicological properties of therapeutics. In addition, OCT2 transports monoamine neurotransmitters [19], thereby participating in the regulation of intracellular and interstitial concentrations of monoamine neurotransmitters and cationic drugs.

Cisplatin-induced nephrotoxicity is a gender dependent; greater intensity of damage in male than female [20]. Gender differences of CPinduced nephrotoxicity may be related to CP uptake by organic cation transporter-2 (OCT2); CP uptake was increased by OCT2 overexpression in male rats and was associated with increased cellular sensitivity to CP toxicity $[21,22]$. Cimetidine, an OCT2 substrate, diminished CP uptake and cytotoxicity in vitro [23] and CP-induced nephrotoxicity in vivo [24]. Inhibition of OCT2 plays a role to the overall therapeutic effects in clinical practice. A recent study demonstrated involvement of OCT2 inhibition in potential mechanisms of antidepressant action. This study tested nine antidepressant agent includes selective serotonin reuptake inhibitors (fluoxetine, sertraline and paroxetine), tricyclic antidepressants (amitriptyline, imipramine, desipramine), monoamine oxidase inhibitor (moclobemide) and serotonin-norepinephrine reuptake inhibitor (venlafaxine) [25]. All of the nine antidepressant compounds displayed moderate inhibitory effects on OCT2-mediated metformin, norepinephrine and/or serotonin uptake; Sertraline

*Corresponding author: Amr A EL-Arabey, Pharmacology and Toxicology Department, Faculty of Pharmacy, Al-Azhar University, Nasr City, Cairo, Egypt, Tel: +39 0187533213; Fax: +390187533045; E-mail: ph.amrcapa@gmail.com

Received September 16, 2015; Accepted October 20, 2015; Published October 26, 2015

Citation: EL-Arabey AA, Abd-Allah AR (2015) Antidepressants as a New Approach for Protective Interventions of Cisplatin-Induced Nephrotoxicity. J Kidney 1: 102. doi:10.4172/2472-1220.1000102

Copyright: (c) 2015 EL-Arabey AA, et al. This is an open-access article distributed under the terms of the Creative Commons Attribution License, which permits unrestricted use, distribution, and reproduction in any medium, provided the original author and source are credited. 
Citation: EL-Arabey A A, Abd-Allah AR (2015) Antidepressants as a New Approach for Protective Interventions of Cisplatin-Induced Nephrotoxicity. J Kidney 1: 102. doi:10.4172/2472-1220.1000102

Page 2 of 2

and desipramine tended to inhibit OCT2 activity via a competitive mechanism [25]. Moreover, a recent study concluded that Sertraline seems to have a protective effect on CP ototoxicity and could be used to treat the depression that occurred in cancer patients together [26]. In addition, a study demonstrated that mirtazapine prevent biochemical and histological changes of lethal CP induced nephrotoxicity and that the protective effects originate from its own antioxidant activity [27].

Depression is a comorbid disabling syndrome that affects approximately $15 \%$ to $25 \%$ of cancer patients [28]. Antidepressants are frequently prescribed concurrently with anti-cancer drugs and may have synergistic, additive or antagonistic effects. The drug-drug interaction between antidepressants and platinum anti-cancer agents requires detailed estimation for optimization of patient care [29]. The effect of antidepressants on platinum cytotoxicity is both cell type and drug dependent. Mostly additive effects were recognized; desipramine and fluoxetine caused the greatest effects, with CP in general being most sensitive to their presence [29]. Moreover, antidepressants are effective in the treatment of depression or depressive symptoms (subclinic depression) in patients with cancer. However, further studies with larger samples are required in order to confirm this conclusion [30]. Interestingly, a recent study provides strong evidence that lung cancer patients taking antidepressants have a significantly prolonged survival [31]. Finally, we suggest research is needed to evaluate potential effect of antidepressants on CP-induced nephrotoxicity through interference of CP uptake by OCT2 to represent ideal renal protective compounds to improve the therapeutic index of $\mathrm{CP}$ and treat depression which occurs in cancer patients together after considering the risk of side effects and interactions.

\section{References}

1. Kodama A, Watanabe H, Tanaka R, Kondo M, Chuang VT, et al. (2014) Albumin fusion renders thioredoxin an effective anti-oxidative and anti-inflammatory agent for preventing cisplatin-induced nephrotoxicity. Biochimica et Biophysica Acta 1840: 1152-1162.

2. Sastry J, Kellie SJ (2005) Severe neurotoxicity, ototoxicity and nephrotoxicity following high-dose cisplatin and amifostine. Pediatr Hematol Oncol 22: 441 445 .

3. Shiraishi F, Curtis LM, Truong L, Poss K, Visner GA, et al. (2000) Heme oxygenase-1 gene ablation or expression modulates cisplatin-induced renal tubular apoptosis. Am J Physiol Renal Physiol 278: F726-736.

4. Kuhad A, Tirkey N, Pilkhwal S, Chopra K (2006) Renoprotective effect of Spirulinafusiformis on cisplatin-induced oxidative stress and renal dysfunction in rats. Ren Fail 28: 247-254.

5. Schmetzer O, Flörcken A (2012) Sex differences in the drug therapy for oncologic diseases. Handb Exp Pharmacol : 411-442.

6. Niho S, Yamanaka T, Umemura S, Matsumoto S, Yoh K, et al. (2013) Rena toxicity caused by brand-name versus generic cisplatin: a comparative analysis Jpn J Clin Oncol 43: 390-395

7. Oboh G, Akinyemi AJ, Ademiluyi AO (2013) Inhibitory Effect of Phenolic Extract from Garlic on Angiotensin-1 Converting Enzyme and Cisplatin induced Lipid Peroxidation - In Vitro. Int J Biomed Sci 9: 98-106.

8. Hensley ML, Hagerty KL, Kewalramani T, Green DM, Meropol NJ, et al. (2009) American Society of Clinical Oncology 2008 clinical practice guideline update: use of chemotherapy and radiation therapy protectants. J Clin Oncol 27: 127145.

9. Castiglione F, Dalla Mola A, Porcile G (1999) Protection of normal tissues from radiation and cytotoxic therapy: the development of amifostine. Tumori 85: 85 91.

10. Miller RP, Tadagavadi RK, Ramesh G, Reeves WB (2010) Mechanisms of Cisplatin nephrotoxicity. Toxins (Basel) 2: 2490-2518.

11. Yonezawa A, Masuda S, Nishihara K, Yano I, Katsura T, et al. (2005) Association between tubular toxicity of cisplatin and expression of organic cation transporter
rOCT2 (Slc22a2) in the rat. Biochem Pharmacol 70: 1823-1831.

12. Ludwig T, Riethmüller C, Gekle M, Schwerdt G, Oberleithner H (2004) Nephrotoxicity of platinum complexes is related to basolateral organic cation transport. Kidney Int 66: 196-202.

13. Motohashi H, Sakurai $Y$, Saito H, Masuda S, Urakami $Y$, et al. (2002) Gene expression levels and immunolocalization of organic ion transporters in the human kidney. J Am Soc Nephrol 13: 866-874.

14. Ciarimboli G, Ludwig T, Lang D, Pavenstädt H, Koepsell H, et al. (2005) Cisplatin nephrotoxicity is critically mediated via the human organic cation transporter 2. Am J Pathol 167: 1477-1484.

15. Koepsell H, Endou H (2004) The SLC22 drug transporter family. Pflugers Arch 447: 666-676.

16. Motohashi H, Uwai Y, Hiramoto K, Okuda M, Inui K (2004) Different transport properties between famotidine and cimetidine by human renal organic ion transporters (SLC22A). Eur J Pharmacol 503: 25-30.

17. Jonker JW, Schinkel AH (2004) Pharmacological and physiological functions of the polyspecific organic cation transporters: OCT1, 2, and 3 (SLC22A1-3). J Pharmacol Exp Ther 308: 2-9.

18. Koepsell H (2004) Polyspecific organic cation transporters: their functions and interactions with drugs. Trends Pharmacol Sci 25: 375-381.

19. Busch AE, Karbach U, Miska D, Gorboulev V, Akhoundova A, et al. (1998) Human neurons express the polyspecific cation transporter hOCT2, which translocates monoamine neurotransmitters, amantadine, and memantine. Mol Pharmacol 54: 342-352.

20. Nematbakhsh M, Ebrahimian S, Tooyserkani M, Eshraghi-Jazi F, Talebi A, et al. (2013) Gender difference in Cisplatin-induced nephrotoxicity in a rat model: greater intensity of damage in male than female. Nephrourol Mon 5: 818-821.

21. El-Arabey AA (2015) Gender difference in Cisplatin-induced nephrotoxicity in a rat model. Nephrourol Mon 7: e23595.

22. El-Arabey AA (2015) Sex and age differences related to renal OCT2 gene expression in cisplatin-induced nephrotoxicity. Iran J Kidney Dis 9: 335-336.

23. Ciarimboli G, Ludwig T, Lang D, Pavenstädt $H$, Koepsell $H$, et al. (2005) Cisplatin nephrotoxicity is critically mediated via the human organic cation transporter 2. Am J Pathol 167: 1477-1484.

24. Ciarimboli G, Deuster D, Knief A, Sperling M, Holtkamp M, et al. (2010) Organic cation transporter 2 mediates cisplatin-induced oto- and nephrotoxicity and is a target for protective interventions. Am J Pathol 176: 1169-1180.

25. Wang K, Sun S, Li L, Tu M, Jiang H (2014) Involvement of organic cation transporter 2 inhibition in potential mechanisms of antidepressant action. Prog Neuropsychopharmacol Biol Psychiatry 53: 90-98.

26. Ozturk M, Ucar S, Sarı F, Erdogan S, Topdag M, et al. (2013) Possible protective effect of sertraline against cisplatin-induced ototoxicity: an experimental study. ScientificWorldJournal 2013: 523480 .

27. Sener MT, Sener E, Tok A, Polat B, Cinar I, et al. (2012) Biochemical and histologic study of lethal cisplatin nephrotoxicity prevention by mirtazapine. Pharmacol Rep 64: 594-602.

28. Lloyd-Williams M, Friedman T (2001) Depression in palliative care patients--a prospective study. Eur J Cancer Care (Engl) 10: 270-274.

29. Engelmann BJ, Ryan JJ, Farrell NP (2014) Antidepressants and platinum drugs. Anticancer Res 34: 509-516.

30. Laoutidis ZG, Mathiak K (2013) Antidepressants in the treatment of depression/ depressive symptoms in cancer patients: a systematic review and metaanalysis. BMC Psychiatry 13: 140

31. Zingone A, Brown D, Bowman E, Vidal O, Neal J, et al. (2015) Abstract LB-182: Improved survival among lung cancer patients taking antidepressants. Cancer Res, 75(15 Supplement), LB-182. 